\title{
PENGEMBANGAN POTENSI PERAIRAN KUALA BUBON PADA NELAYAN KEPITING DESA ALUE RAYA KECAMATAN SAMATIGA KABUPATEN ACEH BARAT
}

\section{THE DEVELOPMENT OF KUALA BUBON WATERS TO CRABS FISHERMEN OF ALUE RAYA VILLAGE SAMATIGA DISTRICT WEST OF ACEH REGENCY}

\author{
Zuriat $^{1}$ \\ ${ }^{1}$ Prodi Perikanan Fakultas Perikanan dan IImu Kelautan Universitas Teuku Umar Meulaboh \\ Korespondensi : utuzuriat@gmail.com
}

\begin{abstract}
ABSTRAK
Desa Alue Raya merupakan sebuah desa di Kecamatan Samatiga yang berhadapan langsung dengan sebuah perairan yang cukup luas yang disebut dengan kuala, dimana didalamnya terdapat berbagai biota sperti kepiting dan ikan .didalamnya juga ditumbuhi oleh tanaman mangrove yaitu Rhizopora stylosa, Rhizopora apiculata $\mathrm{Bl}$ dan Nypa fruticans. Kawasan pesisir ini juga terdapat beberapa desa lainnya seperti desa Kuala Bubon dan lainnya, yang mengelilingi perairan kuala. Permasalahan yang dialami oleh para nelayan yang melakukan kegiatan penangkapan kepiting dengan menggunakan bubu, yakni berkurangnya produksi hasil tangkapan dari tahun ke tahun. Lima tahun yang lalu, hasil tangkapan kepiting masih dapat digunakan untuk mencukupi kebutuhan belanja rumah tangga dengan hasil 2 sampai $4 \mathrm{~kg}$ perhari. Namun saat ini pada tahun 2017, hasil tangkapan hanya 1 sampai $2 \mathrm{~kg}$. Permasalahan prioritas adalah berkurangnya stok kepiting di perairan tersebut. Untuk mengatasi permasalahan jangka panjang, maka perlu dilakukan penebaran kembali atau restocking kepiting dan pengaturan aktifitas penangkapan dengan ukuran tubuh dan tingkat kematangan gonad. Kegiatan pengabdian masyarakat yang telah dilakukan meliputi kegiatan identifikasi permasalahan dan pembentukan kelompok serta pengajuan usulan ke pihak pemkab Aceh Barat untuk membantu penambahan stock kepiting.
\end{abstract}

Kata Kunci : Perairan, Kepiting Bakau dan Kelompok Nelayan

\section{ABSTRACT}

Alue Raya village is a subdistrict in Samatiga District that face directly with enough wide water that called river which there are several biota like crabs and fish that grew by mangrove plant including Rhizoporastylosa, RhizoporaapiculataBI danNypa fruticans. This coastal area also existed in some villages like Kuala Bubon and others that surrounded by river waters. The problem that experienced by fishermen that catch the crabs by using trap namely decreased production of crabs from year to year. Five years ago, the fishing yield still used for fulfilling their household necessesary with $2-4 \mathrm{~kg} /$ day. However, in 2017 , the fishing yield only $1-2 \mathrm{~kg} / \mathrm{day}$. The priority problem is decreasing crabs stock in such water. To overcome this long term problem. Thus, it is necessary to undertaken crabs restocking and the control of fishing activity with body size and gonad maturity level. The community serving activity that undertaken including problem identification and forming community group as well as to propose the proposal to west of Aceh Government for helping addition of crabs stock.

Key words : waters, Crabs, and Fishermen group 


\section{PENDAHULUAN}

Kabupaten Aceh Baratadalah salah satu Kabupaten yang memilki potensi sumberdayaperikanan, baik perikanan laut maupun perairan umum berupa sungai dan rawa. Kegiatan penangkapan kepiting di kawasan rawa kuala Bubon, berlasung setiap hari dengan menggunakan perangkap berupa bubu yang terbuat dari jaring. Luas perairan umum berdasarkan Data Statistik Kabupaten Aceh Barat dalam Angka adalah seluas300 Ha (BPS, 2016).

Gampong Alue Raya merupakan salah satu desa dari beberapa desa yang ditumbuhi oleh tanaman nipah, dengannsumber air muara Kuala Bubon yang merupakan air payau. Kelompok nelayan kepiting adalah semua nelayan yang melakukan kegiatan penangkapan kepiting di perairan umum kuala bubon yang berjumlah sebanyak 24 orang, namun nelayan ini belum berkelompok secara administrasi, kegiatan usaha yang dilakukan adalah secara mandiri.Namun jumlah nelayan kepiting jumlahnya sangat terbatas, karena terbatasnya stock biota dalam perairan. Kepiting bakau adalah adalah salah satu biota perikanan yang hidup di air payau, tawar dan laut. Kepiting bakau adalah jenis kepiting yang hidupdi air payau,menurut Nurdin dan Armando (2011) ada empat jenis kepiting bakau yang di temui di Indonesia, yaitu kepiting bakau merah (Scylla olivacea) atau red/orange mud crab, kepiting bakau hijau ( $S$. Serrata) atau giant mud crab, karena ukurannnya yang dapat mencapai 2 - $3 \mathrm{~kg} / \mathrm{ekor}$, kepiting bakau ungu ( $S$. Tranguebarica) juga dapat mencapai ukuran besar dan kepiting bakau putih (S. Paramamosain).

Dari pemantauan tersebut, maka saya berinisiatif untuk melakukan pembinaaan agar nelayan ini dapat disatukan dalam satu wadah kelompok, untuk melakukan kegiatan penangkapan dan berinteraksi dalam pengembangan kawasan yang lebih produktif dan berkelanjutan. Terbatasnya stock kepiting di perairan kuala buboen, menjadikanpendapatan nelayan menaglami penurunan, pada nelayan adalah orang yang pekerjaannya melakukan penangkapan ikan (UU No. 45, thn 2009).

Jumlah anggota kelompok nelayan kepiting adalah sebanyak 24 orang yang berasal dari beberapa Gampoeng, yakni gampoeng Alue Raya dan sekitarnya. Nelayan kepiting yang melakukan kegiatan penangkapan kepiting belum menyatu dalam wadah kelompok. Kebutuhan akan ikan semakin hari semakin meningkat, sehubungan dengan pertambahan populasi penduduk dan kesadaran akan konsumsi ikan, membuka peluang bagi para pembudidaya ikan, terutama yang sudah ada kolam untuk melakukan pemeliharaan ikan secara bussiness oriented.

Usaha penangkapan kepiting di kawasan sumberdaya alam yang berbasis pada rawa nipah muara KualaBubon Kecamatan samatiga Kabupaten Aceh Barat perlu dicermati sebagai usaha penangkapan potensi sumberdaya perikanan yang telah berlangsung lama. Dimana saat ini yelah mengalami stagnan, dalam arti tidak mengalami peningkatan hasil tangkapan dan pendapatan, namun tetap bertahan dengan kondisi yang mengalami penurunan tingkat produksi. Didalam landasan filosofis juga terkait dengan religius masyarakat aceh yang menganggap bahwa sumberdaya hayati merupakan anugerah Allah SWT, oleh karena itu sumber daya hayati yang terdapat didarat dan dilaut harus dimanfaatkan untuk kemakmuran dan kesejahteraan umat, baik untuk generasi sekarang maupun yang akan datang (Tripa, 2012). 


\section{Rumusan Masalah}

Permasalahan yang diperoleh pada kelompok ini saat ini adalah, bahwa hasiltangkapan cenderung menurun dan ukuran kepiting juga rata-rata mengecil dan masalah lai yang ditemui permasalahan sebagai berikut :

1. Menurunnya tingkat perolehan hasi Itangkapan kelpiting

2. Kurangnya atau sulitnya memperoleh umpan dan harga mahal

3. Kerjasama kelompok masih rendah

4. Masih kurangnya perhatian pihak terkait dalam pembinaan dan pengembangan potensisumberdaya perairan

\section{Maksud dan Tujuan}

Adapun maksud dan tujuan dari kegiatan pengabdian masyarakat ini adalah sebagai berikut :

1. Sebagai kewajiban penulis dalam hal Tri dharma perguruan tinggi, yang salah satunya adalah pengabdian pada masyarakat.

2. Membantu nelayan dalam hal mengaktifkan organisasi kelompok.

3. Memberikan bimbingan teknis dalam kegiatan restocking untuk populasi kepiting.

4. Membantu pembuatan usulan ke instansi terkait untuk kegiatan restocking.

\section{METODE PELAKSANAAN}

\section{Lokasi dan Waktu}

Pelaksanaan pertemuan dalam pembinaan dimaksudkan sebagai upaya mencapai keberhasilan usaha penangkapan yang berkelanjutan dalam bentuk diskusi bersama anggota kelompok dengan merekap terlebih dahulu permsalahan yang telah dan akan dihadapi dalam usaha penangkapan dan pelestarian potensi sumberdaya kepiting (Gambar 1). Waktu pelaksanaan kegiatan pembinaan dan bimbingan keanggotaandilaksanakan pada tanggal 5 - 7 April 2017 dan pembinaan berkelanjutan, dengan kegiatan sebagai berikut :

1. Pertemuan kelompok, yang di hadiri oleh 12 orang anggota kelompok sebagaimana daftar hadir terlampir.

2. Pendataan anggota kelompok.

3. Pencerahan pengetahuan biologi dan pengembangan kepiting

4. Peninjauan lokasi panangkapan kepiting

5. Temu wicara dan pembinaan usaha dalam keberlangsungan populasi kepiting

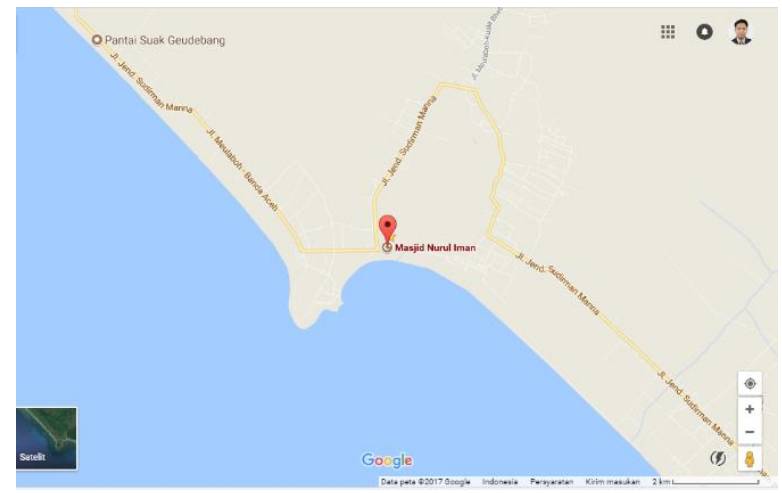

Gambar 1. Lokasi Pengabdian Kepada Masyarakat 


\section{Metode Pelaksanaan}

Metode pelasanaan pengabdian pada masyarakat ini mengambil metode pembinaan kelompok sebagai berikut :

a. Melakukan pertemuan kelompok

b. Memberikanan bimbingan manajemen usaha penangkapan

c. Membantu membuat usulan kebutuhan kelompok ke instansi Pembina, yang dalam hal ini adalah Dinas Kelautandan Perikanan setempat, untuk diadakan restoking terhadap populasi kepiting.

Metode pelaksanaan dengan menggunakan teknik pendekatan partisipatif dan informatif,bagi nelayan yang berada di DesaAlue Raya yang pelaksanaan aktifitas pengabdian dengan pendekatan partisipatif, untuk memanmpung aspiratif dalam pemanfaatan kawasan penangkapan kepiting bakau dan upaya pengembangannnya yang dilaksanakan melalui tiga langkah sebagai berikut:

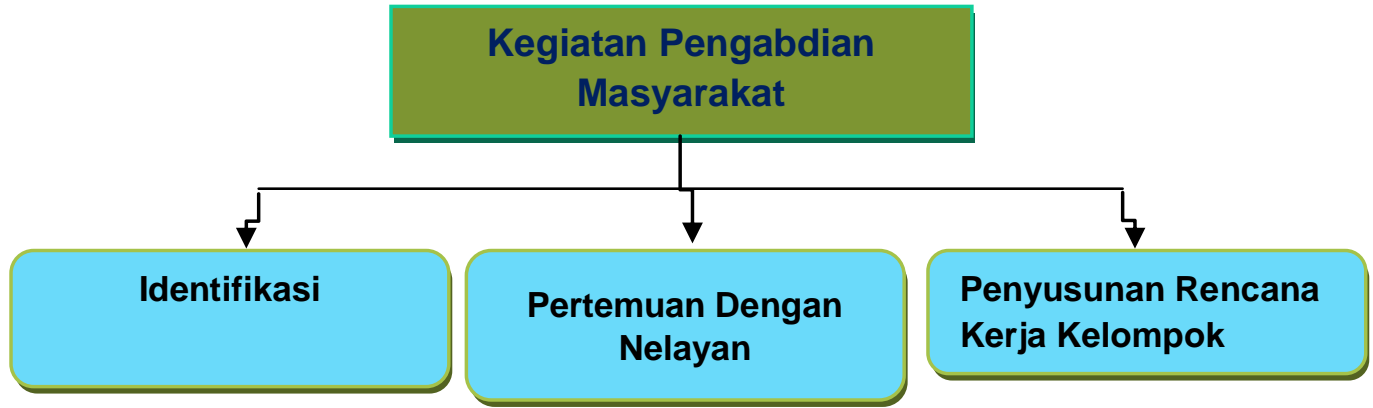

HASIL DAN PEMBAHASAN

Identifikasi lokasi dan Alat tangkap

Hasil identifikasi lokasi menunjukkan bahwa, lokasi perairan terletak di lintasan yang sangat strategis, yakni berhadapan dengan jalan raya Meulaboh Banda Aceh, dan dikelilingi oleh beberapa pemukiman penduduk, serta berhadapan dengan muara nya dengan laut lepas. Berdasarkan letak lokasi ini, sangat potensial untuk dikembangkan sebagai sumber produksi kepiting dan pendapatan nelayan. Perairan kuala Bubon termasuk kedalam wilayah pesisir yang potensial untuk dikembangkan. Alat tangkap yang digunakan oleh nelayan adalah jenis alat tangkap bubu.... Bubu adalah sejenis alat perangkap dengan menggunakan umpan. Gambar 2 ini adalah jenis alat yang digunakan, yang diperagakan oleh ketua kelompok, yang biasanya dipanggil bang Toto, sekaligus berperan sebagai toke yang menampung hasil kepiting hasiltangkapan nelayan (Gambar 2).

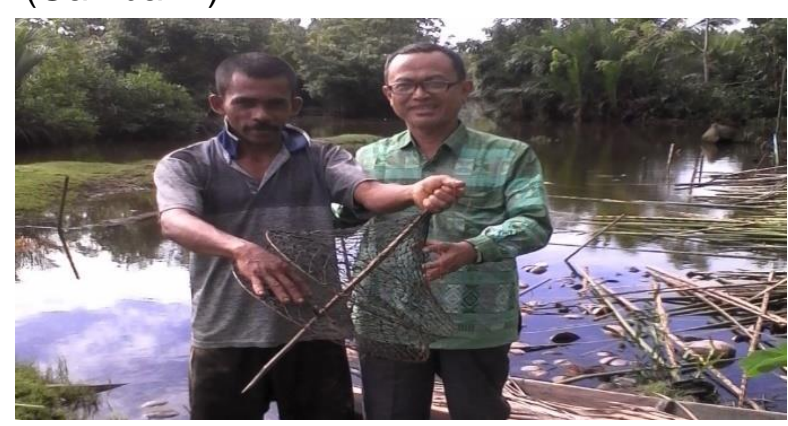

Gambar 2. Percobaan alat tangkap bubu kepada nelayan kepiting Sumber : (Dokumentasi Lapangan, 2018). 


\section{Tingkat Partisipasi}

Sebagai hasil dari pelaksanaan bimbingan dalam pertemuan dimana diikuti oleh beberapa anggota kelompok sebagai perwakilan dari anggota nelayan kepiting, yaitu sebanyak 7 orang, sedangkan lainnya belum dapat hadir sebagaimana diketahui bahwa masyarakat mempunyai kesibukan yang beraneka ragam (Gambar 3).

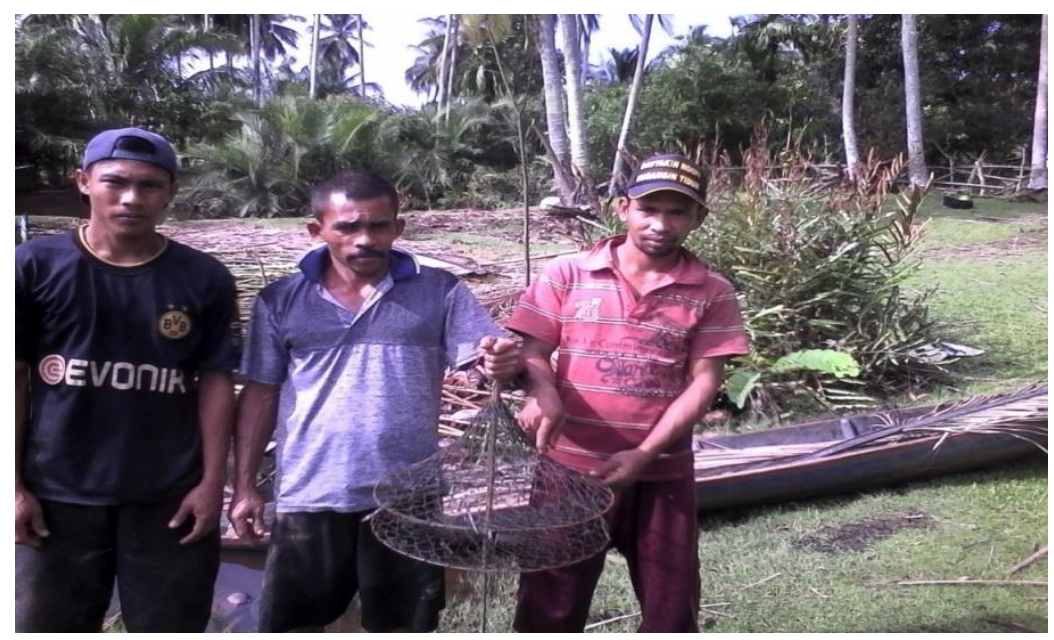

Gambar 3. Kegiatan pertemuan dengan kelompok nelayan kepiting Sumber : (Dokumentasi Lapangan, 2017).

\section{Rencana Aksi Kelompok}

Adapun rencana dari hasil pertemuan ini adalah bahwa anggota nelayan membentuk kelompok yang beranggotakan seluruh nelayan yang melakukan kegiatan penangkapan kepiting dari beberapa desa yang masuk dalam kawasan muara Kuala Bubon yang luasnya sekitar $300 \mathrm{Ha}$.

\section{Penguatan Kelompok}

Untuk langkah selanjutnya akan dilakukan penguatan kelompok, akan di buat pos kelompok yang berlokasi di areal lokasi penangkapan kepiting, disalah satu pondok yang akan ditetapkan kemudian hari.

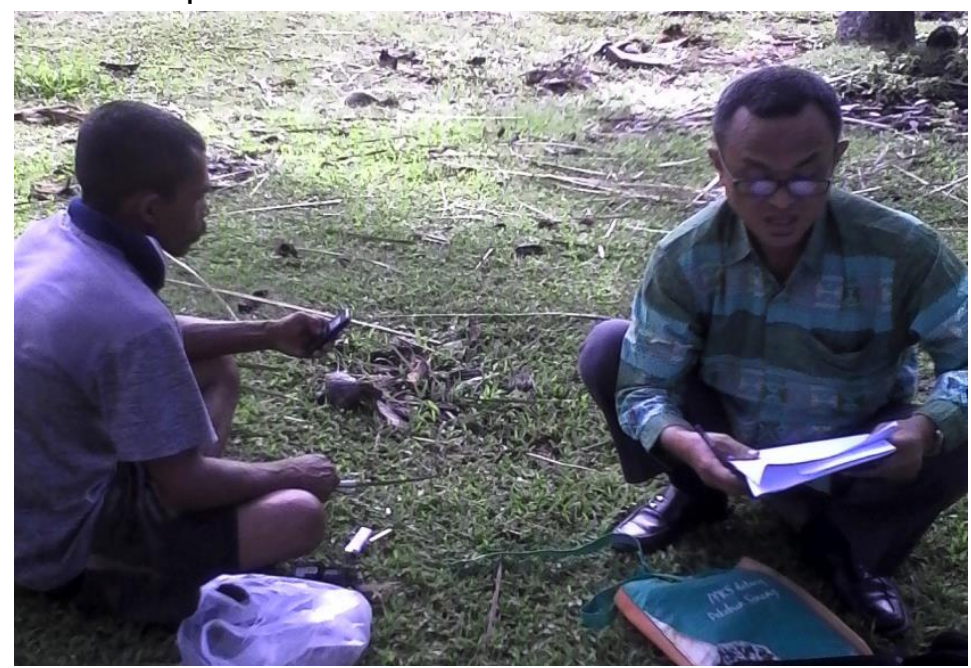

Gambar 4. Interview dengan nelayan kepiting bakau dalam penguatan kelompok Sumber : (Dokumentasi Lapangan, 2017). 


\section{Pelaksanaan Aktifitas Kelompok}

Dalam pelaksanaan kegiatan usaha penangkapan kepiting yang berkelanjutan, diperlukan organisasi kelompok yang kuat, melalui penguatan organisasi dan penguatan potensi yang akan ditempu dengan langkah-langkah sebagai berikut :

1. Menjaga lingkungan kawasan kuala dari berbagai pencemaran lingkungan

2. Dibuat aturan kelompok dalam menjaga kelestaian sumberdaya dan keberlanjutan

3. Untuk maksud tersebut akan segera dibuat proposal kedinas kelautan dan perikanan Kabupaten Aceh Barat yakni proposal permohonan bibit kepiting guna pelestaian kepiting yang akan ditebar dalam kolam pemijahan.

Pada langkah awal, kami melakukan kegiatan penyemaian bibit mangrove yang dilakukan pada pagi hari bersamamasyarakat pesisir. Untuk kebutuhan penyemaian bibit mangrove yaitu dengan mencari bibit mangrove yang sudah tua atau buah yang telahjatuh. Kemudian dipindahkan ke dalam wadah polibag.Bibit mangrove tersebut diletakkan di daerah yang terkena dengan pasang surut air laut. Hal ini dilakukan agar bibit mangrove tersebut selalu terkena air sehingga meminimalisir tingkat kematian (Gambar 5).

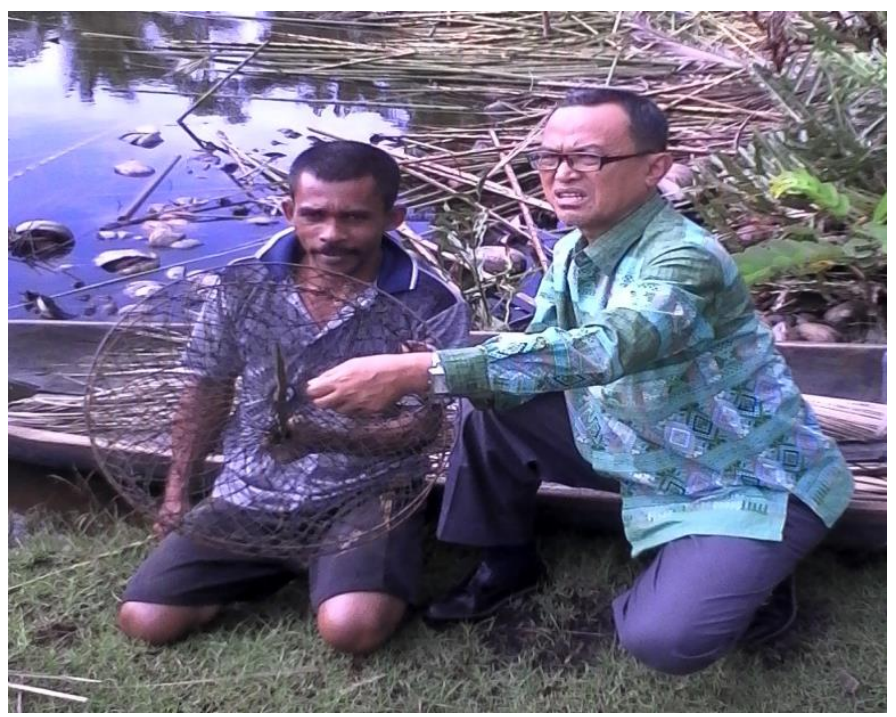

Gambar 5. Pelaksanaan Aktivitas Kelompok nelayan alat tangkap kepiting Sumber : (Dokumentasi Lapangan, 2017)

\section{Penguatan Kelompok}

Dari hasil pengamatan dan kesepakatan kelompok, perlunya dilakukan tindak lanjut melalui pembinaan yang berkelanjutan, baik dalam meningkatkan produksi stok kepiting diperairan maupun dalam pengaturanpenangkapandalam upaya meningkatkan pendapatan nelayan. Tindak lanjut dari dari hasil pertemuan adalah menyusun secara lengkap susunan kelompok dan membuat aturan kelompok, yang akan dilaksanakan dalam waktu selanjutnya yang diharapkan dapat dihadiri oleh seluru anggota nelayan kepiting.

\section{Penguatan Teknik Penangkapan}

Perkembangan usaha penangkapan sebenarnya bukan hanya kegiatan menangkap, namun harus disertai dengan kegiatan memperbanyak biota disuatu 
kawasan, yang dalam hal ini disamping melakukanpenangkapan kepiting,bagaimana pula dapat menambah stok kepiting melalui kegiatan pengembangan perbanyakan kepiting secara alami disuatu kawasan reservat.

Kepiting awal hidupnya mempunyai daur hidup dan bertelur di Muara dan dapat meneruskan hidupnya didalam perairan Kuala Bubon. Namun, jika dalam waktu singkat kepitingn tidak dapat menemukan pakan yang sesuai dengan bukaan mulutnya, maka ikan itu akan menjadi lemah dan selanjutnya mati. Hal ini menyebabkan kepiting pada tingkat larva mengalami kematian yang cukup tinggi. Sifat pakan alami yang bergerak yang tidak terlalu aktif, memudahkan larva menangkapnya. (Priyambodo dan Wahyuningsih, 2004). Dengan demikian maka, diperlukan langkahlangkah untuk memperbanyak kepiting dengan jalan menambah volume kepiting dari perairan luar, dan ditempatkan dalam reservat yang terkendali.

\section{Penguatan Permodalan dan Pemasaran Hasil}

Modal yang diperlukan untuk melakukan kegiatan penangkapan kepiting tidak besar, yakni hanya sebesar Rp. 1 juta rupiah, untuk sampan dan bubu jaring. Demikian juga dalam halpemasaran hasil tangkapan dijual di rumah makan yang ada di kawasan penangkapan kepiting dengan harga Rp. 50.000/Kg. Namun jika ukuran kepiting nya besar yng berukurn dits 300 gram, maka harganya lebih tinggi yang mencapai Rp.80.000,-. Upaya penguatan modal dan pemasaran hasil, perlu diperkuat kelembagaan kelompok, dengan membentuk susunn pengurus dan aturan serta rencana kerja kelompok.

Untuk itu, telah dibentuk susunan pengurus kelompok dan dibuatkan usulan peningkatanstock kepiting melalui pelepasan kepiting ke instansi pemkab Aceh Barat.

\section{KESIMPULAN DAN SARAN Kesimpulan}

Dari kegiatan pengabdian ini, mendapatkan sambutan yang cukup baik dari para nelayan dan diharapkan dapat dilakukan pembinaan berkelanjutan untuk pemberdayaan potensi sumberdaya perikanan yang berkelanjutan bersama nelayan.Kepiting adalah komoditi perikanan yang mana mempunyai nilai ekonomi yang cukup baik, dan perlu upayan peningkatan pendapatan melalui peningkatan stock. Untuk itu, nelayan memerlukan wadah dalam bentuk kelompok, sehingga dapat mendiskusikan hal-hal yang berkenaaan dengan usaha dan pengembangannya.

\section{Saran}

Untuk itu, perlu secara berkala dilakukan pertemuan dan atau pendampingan dengan kelompok tersebut dan peran pembinaan dari instansi yang berkompeten perlu dirtingkatkan. Selain itu, perlu dilaksanakan pertemuan berkala dan pembuatan proposal yang ditujukan kepada pemerintah untuk pengembangan potensi dan pemberdayaan ekonomi nelayan serta memperkuat kelompok.

\section{Ucapan Terima Kasih}

Penulis mengucapkan terima kasih kepada Keuchick Gampong Alue Raya yang telah memfasilitasi kegiatan pengabdian kepada masyarakat. Selain itu, tak lupa pula 
ucapan terima kasih setinggi-tingginya kepada kelompok nelayan kepiting yang memberikan waktu dan kesempatan dalam melakukan kegiatan pengabdian kepada masyarakat di Gampong Alue Raya.

\section{DAFTAR PUSTAKA}

BPS 2012. Kecamatan Samatiga Dalam Angka, Badan Pusat Statistik. Aceh Barat.

Afrianto, E. dan E. Liviawaty. 1992. Pemeliharaan kepiting. Kanisius. Yogyakarta.

Ghufran. M. H. Kordi K, 2012. Ekosistem Mangrove: Potensi, Fungsi danPengelolaan. PT Rineka Cipta. Jakarta.

Kasry, A. 1991. Budidaya Kepiting Bakau dan Biologi Ringkas. Penerbit PT. Bhratara Niaga Medan, 105Jakarta.

Soim, A. 1994. Pembesaran Kepiting. Swadaya. Jakarta

Sudrajat. 2007. Teknologi Untuk Pemberdayaan Masyarakat Pesisir, Seri Budidaya. Direktorat Pemberdayaan Masyarakat Pesisir, Direktorat Jenderal Kelautan, Pesisir Dan Pulau-Pulau Kecil. Kementerian Kelautan Dan Perikanan. Jakarta.

Tripa, S. 2012. Model Kebijakan Pengelolaaan Perikanan, Pusat Studi Hukom Adat Laot, Unsyiah. Banda Aceh. Priyambodo Dan Wahyuningsih, 2004) Budidaya Pakan Alami Untuk Ikan, Penebar Swadaya, Jakarta 